\title{
Superior and Inferior Paraaortic Paraganglioma
}

National Cancer Institute

\section{Source}

National Cancer Institute. Superior and Inferior Paraaortic Paraganglioma. NCI

Thesaurus. Code C48317.

A benign or malignant extra-adrenal sympathetic paragang lioma arising from

paragang lia located along the aorta, including suprarenal, infrarenal, and renal hilar sites.

In functional tumors, the hypersecretion of catecholamines results in hypertension. 